\title{
Conserved SQ and QS motifs in bacterial effectors suggest pathogen interplay with the ATM kinase family during infection
}

Davide Sampietro ${ }^{1,2}$, Hugo Sámano-Sánchez ${ }^{2,3}$, Norman E. Davey ${ }^{4}$, Malvika Sharan ${ }^{2}$, Bálint Mészáros ${ }^{2,5}$, Toby J. Gibson² , Manjeet Kumar,",

1. Department of Biotechnology and Biosciences, University of Milano-Bicocca, Piazza della Scienza 2, 20126 Milan, Italy.

2. Structural and Computational Biology Unit, European Molecular Biology Laboratory, Heidelberg, 69117, Germany

3. (Candidate for) Joint PhD degree from EMBL and Heidelberg University, Faculty of Biosciences.

4. UCD School of Medicine \& Medical Science, University College Dublin, Belfield, Dublin 4, Ireland.

5. MTA-ELTE Momentum Bioinformatics Research Group, Department of Biochemistry, Eötvös Loránd University, Budapest $\mathrm{H}-1117$, Hungary.

* Corresponding author: manjeet.kumar@embl.de

\begin{abstract}
Understanding how bacteria hijack eukaryotic cells during infection is vital to develop better strategies to counter the pathologies that they cause. ATM kinase family members phosphorylate eukaryotic protein substrates on Ser or Thr residues followed by Gln. The kinases are active under oxidative stress conditions and/or the presence of ds-DNA breaks. While examining the protein sequences of well-known bacterial effector proteins such as CagA and Tir, we noticed that they often show conserved (S/TQ) motifs, even though the evidence for effector phosphorylation by ATM has not been reported. We undertook a bioinformatics analysis to examine effectors for their potential to mimic the eukaryotic substrates of the ATM kinase. The candidates we found could interfere with the host's intracellular signaling network upon interaction, which might give an advantage to the pathogen inside the host. Further, the putative phosphorylation sites should be accessible, conserved across species and, in the vicinity to the phosphorylation sites, positively charged residues should be depleted. We also noticed that the reverse motif $(\mathrm{QT} / \mathrm{S})$ is often also conserved and located close to (S/TQ) sites, indicating its potential biological role in ATM kinase function. Our findings could suggest a mechanism of infection whereby many pathogens inactivate/modulate the host ATM signaling pathway.
\end{abstract}

\section{INTRODUCTION}

Clinical data have uncovered a clear connection between several molecular-level biological processes in the human cell, such as oxidative stress response and DNA 
bioRxiv preprint doi: https://doi.org/10.1101/364117; this version posted August 2, 2018. The copyright holder for this preprint (which was not certified by peer review) is the author/funder, who has granted bioRxiv a license to display the preprint in perpetuity. It is made available under aCC-BY-NC-ND 4.0 International license.

BioRxiv: SQ-QS, Effectors and ATM

damage repair, and pathogenic infections. Specifically, the exact molecular steps through which pathogens modulate such host processes are largely unknown. However, several human kinases are known to be critical components of affected pathways and they are considered as candidate targets for pathogenic intervention.

Phosphatidylinositol-3 kinase-related kinases (PIKKs) encompass several Ser/Thr-protein kinases which share sequence similarity with lipid phosphorylating phosphatidylinositol-3 kinases (PI3Ks) (1). In humans, there are six different PIKK members: AtaxiaTelangiectasia Mutated (ATM), Ataxia- and Rad3-related (ATR), DNA-dependent Protein Kinase catalytic subunit (DNA-PK), mammalian Target Of Rapamycin (mTOR), Suppressor of Morphogenesis in Genitalia (SMG-1) and Transformation/Transcription domainAssociated Protein (TRRAP) (1). ATM, ATR and DNA-PK are involved both in the cell cycle DNA damage checkpoints $(2,3)$ and more generally in oxidative stress response $(4 ; 5)$. Even though ATM is mainly considered a nuclear cell cycle kinase, there are several pieces of evidence suggesting it is also localised and functional in the cytosol (6 - 8). Similarly, there is experimental evidence for ATR also being present in the cytosol, although its role is still poorly understood (9). Additionally, DNA-PK was reported to be present in the cytosol where it can activate the transcription of type I interferon (IFN), cytokine and chemokine genes during viral infections (10).

Patients with ATM mutations suffering from Ataxia Telangiectasia (AT) display a progressive loss of neurons (11). Given that neurons are non-dividing cells, this AT phenotype is an indication that ATM has roles outside of cell cycle checkpoints. AT patients are known to be immunodeficient and are especially susceptible to pulmonary infections $(12,13)$. Airway epithelial cells of AT patients have been found to be very sensitive to oxidative insult during Streptococcus pneumoniae infection (14). Certain pathogens deliberately exploit the DNA damage signaling systems. Several of them, including certain Escherichia coli strains, inject genotoxins into host cells, such as the Cytolethal Distending Toxin (CDT) nucleases which create double-strand DNA (ds-DNA) breaks: the resultant ATM damage response can lead to apoptosis of the targeted cells (15). By contrast, Human papillomavirus 16 (HPV16) requires a more controlled ATM activation of the DNA damage repair system for viral genome activation (16).

ATM, ATR and DNA-PK (hereafter referred to as AADks) phosphorylate a wide range of substrates at a Ser-GIn or Thr-GIn (pS/TQ) motif (17). However, in addition to this minimal essential dipeptide, there are preferences for hydrophobic and negatively charged residues $\mathrm{N}$-terminal to the $\mathrm{S} / \mathrm{TQ}$ site; conversely, positively charged residues are underrepresented in the proximity of the phosphorylation (S/TQ) site (17). SQ and TQ are examples of Short Linear Motifs (SLiMs), which are small modules of a protein sequence mediating protein-protein interactions. SLiMs are frequently located in intrinsically disordered protein (IDP) regions. Since disordered regions are not involved in stably folded protein structure formation, mutations are usually more tolerated: Residue conservation in these regions is expected to be indicative of function $(18,19)$. Several known substrates of AADks have clusters of many S/TQs, for example BRCA1, Chk2 and most strikingly FUS (20). However, it is currently unclear what is the cellular purpose for those clusters of SQ sites, given that other AADks substrates, such as H2AX and p53, can fulfil their biological roles by having just a single major site (21).

Proteins such as CDT that are introduced into the host cell by bacteria via various secretory systems are termed effectors (22). Using effectors, pathogenic bacteria can 


\section{BioRxiv: SQ-QS, Effectors and ATM}

hijack the host cell system in order to sustain themselves against the immune response and favour their own replication in a series of processes called host-pathogen interactions (23). Up to now, six different secretory systems (TSS) have been described in Gram-negative bacteria (24); Gram-positive bacteria can use either a specialised apparatus called the injectisome or use additional components in order to introduce the effector into the cytoplasm of the host cell (25). Apart from the six TSS's in Gramnegative bacteria, a seventh one has also been identified exclusively in the members of the genus Mycobacteria (26). In addition, bacteria may use other ways to secrete proteins such as the classical secretion pathway (Sec) or the twin-arginine pathways (Tat pathways) $(27,28)$. Despite our extensive knowledge of TSS, for many effectors the exact mechanism of secretion is still unknown. T3SS, T4SS and T6SS can cross both the bacterial and eukaryotic cellular membrane (24). Even though translocating a protein is energetically expensive (29), Enteropathogenic E. coli (EPEC) uses T3SS to translocate the Translocated-intimin receptor (Tir) effector into the host plasma membrane of intestinal epithelial cells. Upon secretion, it interacts with cytoplasm-located TNF $\alpha$ receptor-associated factor (TRAF) causing its degradation and the inactivation of NF-kB (30). Other bacteria use T4SS: this is the case for Helicobacter pylori, which employs this system to introduce CagA into gastric cells, thereby making it able to interact with a set of host cell regulatory proteins (31). Further, as with viruses (32), bacterial effector proteins can also mimic SLiMs in order to successfully carry out infection. The concept of molecular mimicry is well established for CagA $(33,34)$ and Tir $(35)$. We have been working to collate these, along with other known effector SLiM mimics into the ELM resource (36).

While reviewing the effectors with published SLiMs, we noticed that many of them, including CagA and Tir had multiple conserved or semi-conserved S/TQs (Table S1). We also noticed that they had conserved or semi-conserved $Q S / T$ motifs, having no associated function yet. When we checked cellular FUS and other ATM substrates, we found that the QS/T motif was also present in multiple copies, suggesting it might have a functional relationship with S/TQs. In this paper, we report a bioinformatics analysis of these motifs in cellular proteins and effectors. Because these two residue motifs are so simple and Ser is the most frequent amino acid found in proteins, there is very little sequence information content to work with, and it is not straightforward to obtain good statistical support. Nevertheless, it is clear that a very broad property of invasive bacterial pathogens is that they have effectors with $S / T Q$ and QS/T motifs, and therefore they may be interacting with the AADks to mimic cellular substrates. Experimental investigation on whether or not these motifs are phosphorylated is desirable, as it might open up new therapeutic strategies.

\section{MATERIALS AND METHODS}

Experimentally validated phosphorylation sites in the substrates of ATM, ATR and DNAPK were retrieved from PhosphositePlus (37) and Phospho.ELM (38). Mouse and rat sequences, human alternative isoforms and autophosphorylation sites were removed. In total, we collected 152 proteins containing 360 experimentally validated pS/TQ sites (Supplementary dataset 1).

The experimentally validated effectors for T3SS, T4SS and T6SS were collected from SecretEPDB (39). Low quality (such as partial sequences) and redundant sequences were 
bioRxiv preprint doi: https://doi.org/10.1101/364117; this version posted August 2, 2018. The copyright holder for this preprint (which was not certified by peer review) is the author/funder, who has granted bioRxiv a license to display the preprint in perpetuity. It is made available under aCC-BY-NC-ND 4.0 International license.

BioRxiv: SQ-QS, Effectors and ATM

removed at $90 \%$ sequence identity cut-off. After the filters, we gathered 1,000 unique sequences (Supplementary dataset 2).

Protein sequences were collected from the UniProt database (40) and were aligned with Clustal Omega (41). The alignments were visualised using the Jalview software (42). To measure sequence conservation, the probability of relative local conservation (43) was used. To create the negative control for the $S / T Q$ and $Q S / T$ site conservation, the entire Human proteome (SwissProt) was downloaded. Subsequently, we extracted proteins having the following gene ontology accession - GO:0005737 (cytoplasm), GO:0005829 (cytosol), GO:0005634 (nucleus), and GO:0005622 (intracellular). From this subset, we removed all the 152 experimentally validated substrates of AADks and all the AADk interactors from IntAct and BioGRID. We collected 8,700 proteins that are not known to interact directly with AADks.

The significance of each peptide was calculated as the distance from a 1:1 correlation line as follows:

$$
Y_{i}=\frac{y_{i}-x_{i}}{\sqrt{2}}
$$

Where $Y_{i}$ is the distance from the $1: 1$ correlation line of the peptide $i, x_{i}$ and $y_{i}$ are the frequencies of the peptide $i$ in the scrambled and original sequences. $A Y_{i}$ higher than 0 means that the peptide $\mathrm{i}$ is overrepresented in the positive control; on the contrary, $a$ lower $Y_{i}$ than 0 indicates that $i$ is enriched in the negative control.

In order to detect the disordered regions of a protein, we used the IUPred software (44). Two minimal lengths ( 8 and 15 amino acids) for the disordered regions were tested. The frequencies of all the 400 possible dipeptides in the disordered region of the human proteome did not vary substantially (Pearson's correlation for the minimal window of 8 versus a minimal window of 15 was $>0.99$ ). Therefore, a disordered region was defined as a sequence with at least 15 consecutive amino acids with an IUPred score $\geq 0.4$. In the mentioned window up to two residues with scores below the threshold were allowed. Statistical analyses were run in R and Python (Numpy and Scipy libraries).

\section{RESULTS}

The increasing use of infectious tissue culture systems has been helpful in identifying bacterial effectors. For some of these, linear motif mimicry has been reported, and so we have been collecting these motifs to enter into the ELM database. One example is the EPIYA motif which occurs as repeats in CagA, where it was found to mimic an eukaryotic substrate (45). While studying conservation of this motif to prepare the ELM resource entry, we noticed that CagA alignments also had conserved SQs, despite a lack of evidence for ATM phosphorylation (Figure S1). We continued to see SQs in other effectors. An example of a bacterial effector, Ipg2844, with a cluster of S/TQs is shown in Figure 1A. It was also evident that the (reverse) QS/T motif also repeats and clusters with the S/TQs (Figure 1). We then realised that the S/TQs and Q/STs cluster in some cellular ATM substrates as well. The cellular protein FUS has twelve S/TQ motifs clustered in the first third quarter of the protein sequence together with a similar number of QS/Ts (Figure 1B). Other effectors, including PopA, PopB, Tir and yhhA, are shown in Figure 1C, highlighting the clusters of $S / T Q$ and $Q S / T$ in their sequences. Although there is no 
bioRxiv preprint doi: https://doi.org/10.1101/364117; this version posted August 2, 2018. The copyright holder for this preprint (which was not certified by peer review) is the author/funder, who has granted bioRxiv a license to display the preprint in perpetuity. It is made available under aCC-BY-NC-ND 4.0 International license.

BioRxiv: SQ-QS, Effectors and ATM

evidence for functional equivalence, these sequence similarities are so striking that they raised questions about whether bacterial effector proteins are generally rich in S/TQ motifs and whether the QS/T motif might be functional in cellular AADk substrates. The answer to these questions will require experimental testing. Therefore, we were interested in undertaking a closer look bioinformatically to see if there is statistical support for these motif associations that would warrant the subsequent experimental work.

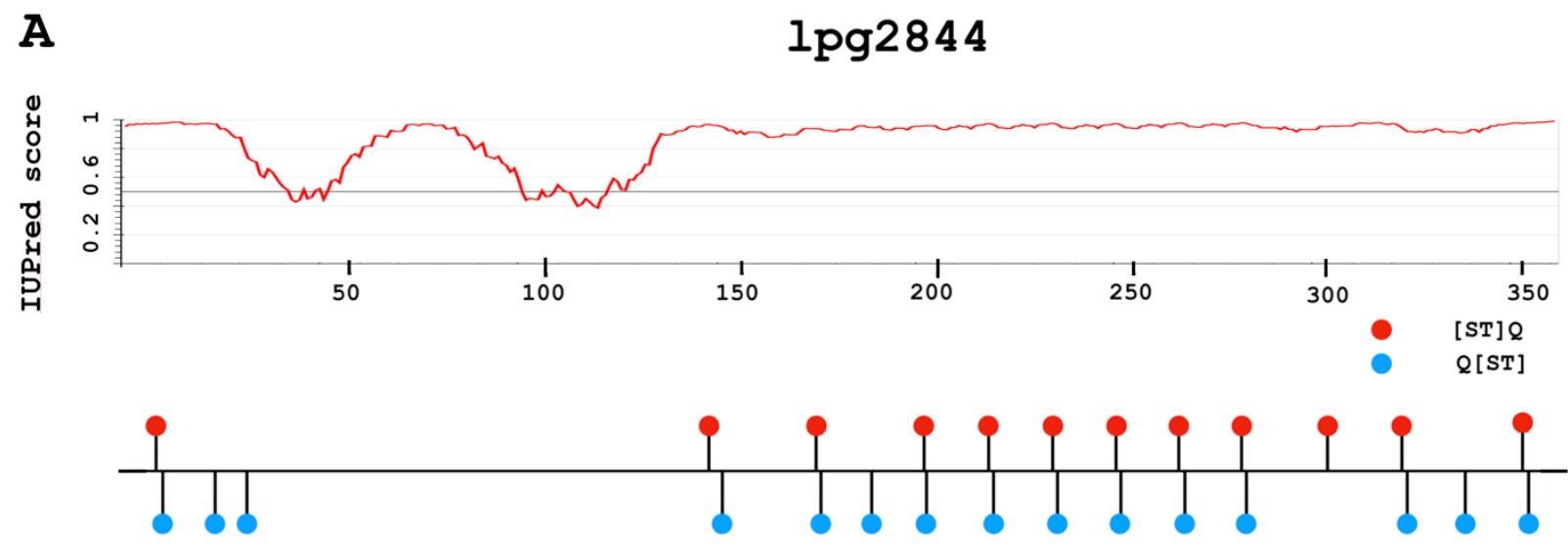

B

FUS

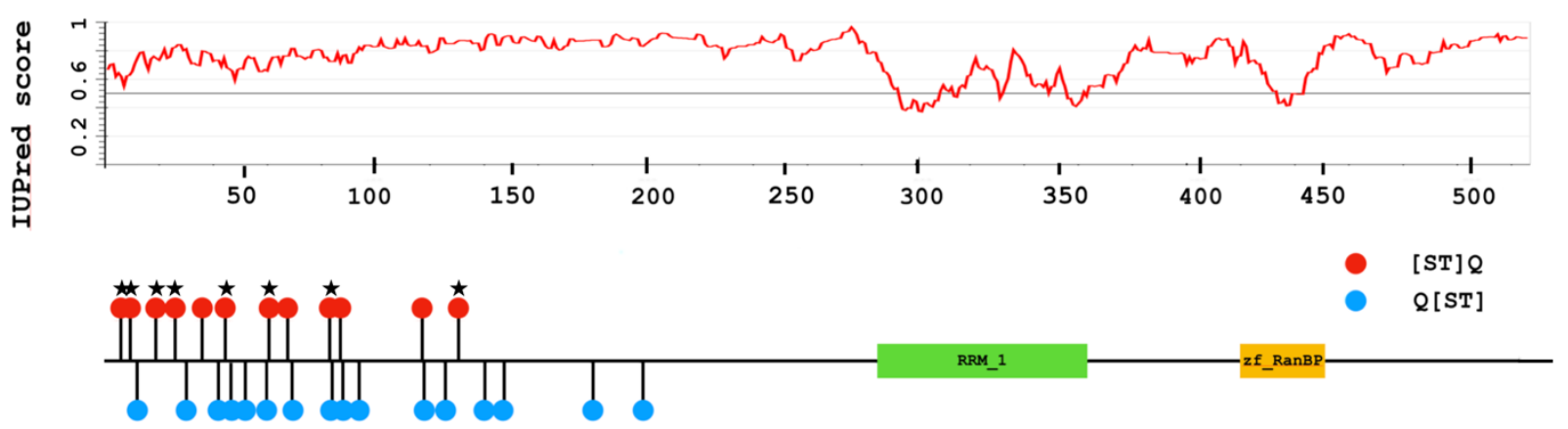

C

PopA

PopB
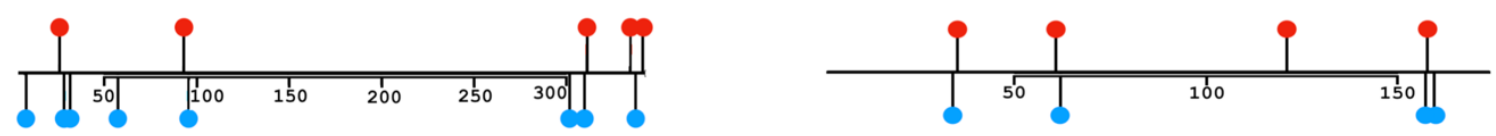

Tir
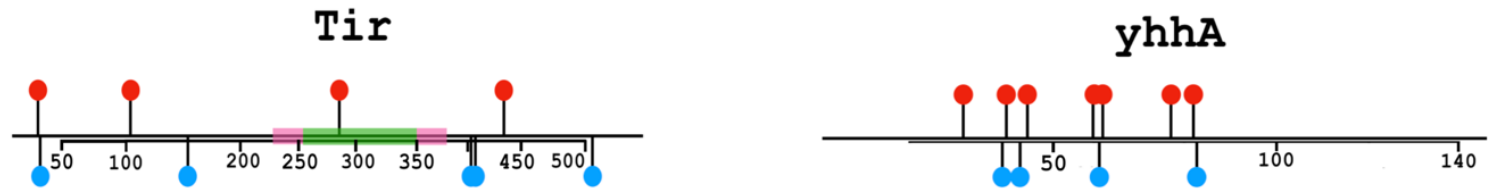

Figure 1. Clustering of S/TQ (red lollipop) and QS/T (blue lollipop) motifs in bacterial effectors and in a cellular ATM substrate. The IUPred plot shows that in both proteins, the motifs are in regions of strong predicted native disorder (score well above 0.5). A: The bacterial effector Igp2844 (UniProt:Q5ZRN6) from Legionella pneumophila is a potential but unproven candidate for a function with FUS-like motif mimicry. B: The subset of S/TQ motifs in the cellular ATM substrate FUS (UniProt:P35637) which are known to be phosphorylated by AADks are marked with a star. The function of the remaining motifs is unknown. C: Other interesting examples include PopA (Q9RBS0) and PopB (Q9RBS1) From Ralstonia solanacearum, Tir (B7UM99) and yhhA (B7UKZ9) from E.coli. For Tir, the topological domains are shown (green for extracellular, pink for helical trans-membrane). It should be noted that the SQ in the extracellular domain of Tir cannot be phosphorylated by AADks. 
bioRxiv preprint doi: https://doi.org/10.1101/364117; this version posted August 2, 2018. The copyright holder for this preprint (which was not certified by peer review) is the author/funder, who has granted bioRxiv a license to display the preprint in perpetuity. It is made available under aCC-BY-NC-ND 4.0 International license.

BioRxiv: SQ-QS, Effectors and ATM

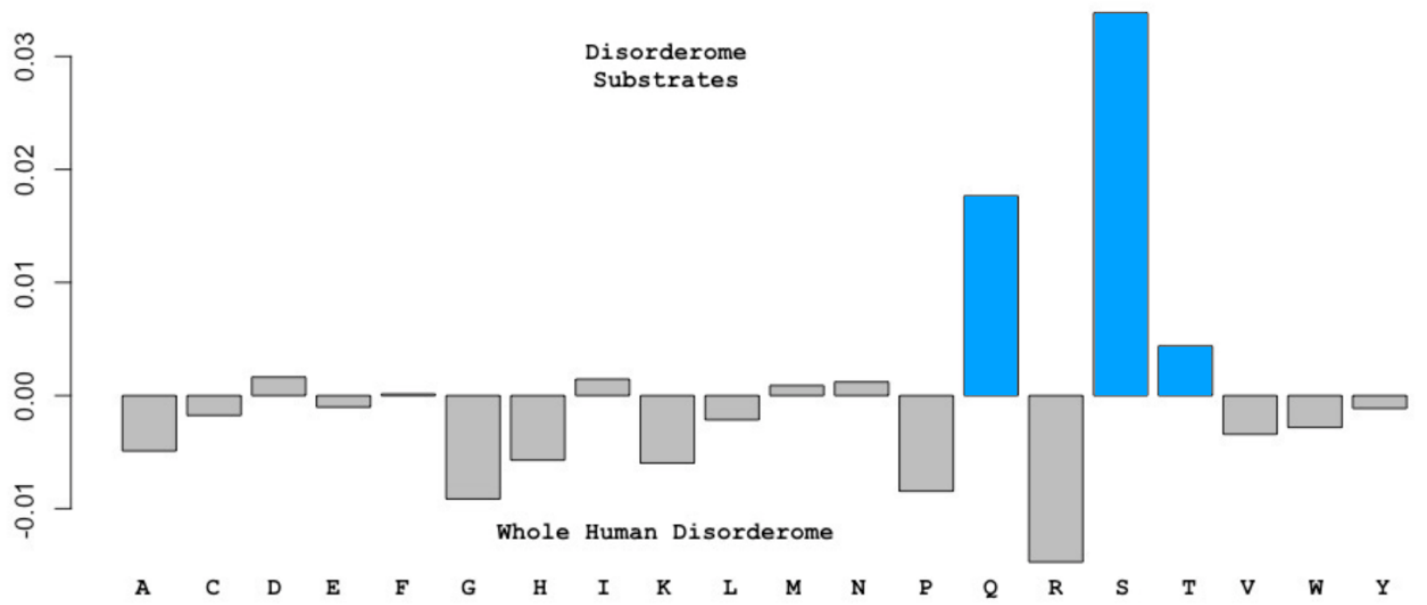

Figure 2. Amino acid frequency in the disordered regions of the substrates versus the whole human disorderome. Each bar represents one amino acid. The relative frequencies are shown in the $y$-axis and a value higher than 0 means that the residue is overrepresented in the disordered regions of the substrates. It should be noted that $S, Q$ and $T$ (light blue bars) are the most abundant residues.
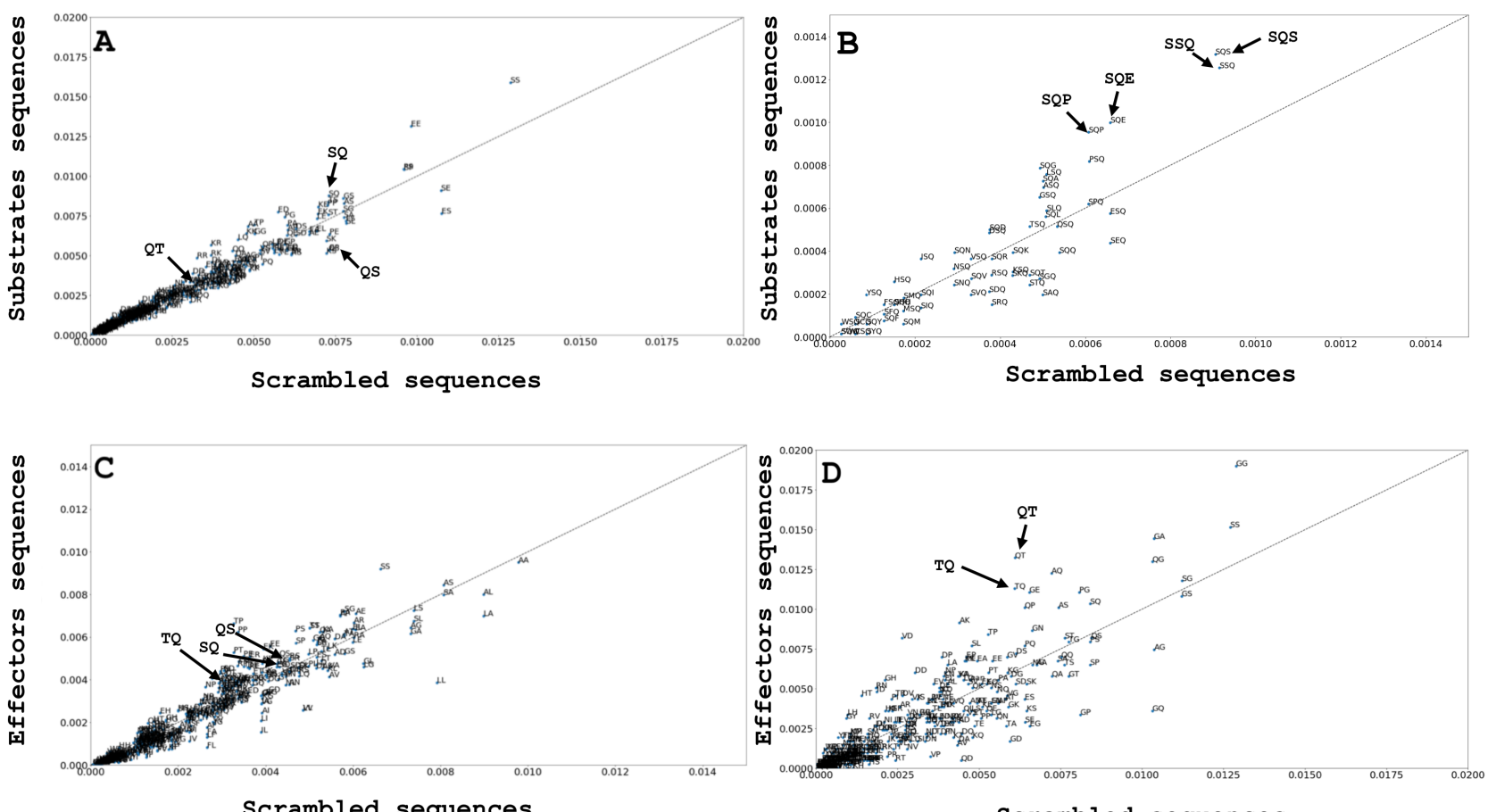

Figure 3. $A$ and $B$ show the frequency of all dipeptides and tripeptides matching the $S x Q, S Q x$ and $x S Q$ regular expression (where $x$ corresponds to any amino acid) in the AADk substrates. C displays the frequency of each dipeptide in the entire set of effectors, whereas $D$ in our effector candidates. The diagonal is the 1:1 correlation line. The further the dot is from this diagonal, the stronger the enrichment. Whatever is above the diagonal is enriched in the positive set.

\section{SQs are enriched in the disordered regions of the substrates}

Very short motifs, such as SQ and QS have low information content. This makes the reliable assessment of the significance of their occurrence challenging. Known functional $S Q$ motifs reside in disordered regions, and considering disordered protein segments in general, Ser and Gln are known to be disorder-promoting (46). A comparison between the disordered regions of the known cellular AADk substrates and the disordered regions of the whole human proteome revealed that Ser, Gln and Thr are the three most overrepresented residues in the substrates (Figure 2). This raises the question whether the high observed number of $\mathrm{S} / \mathrm{TQ}$ sites is significant or is it purely by random chance in the 
bioRxiv preprint doi: https://doi.org/10.1101/364117; this version posted August 2, 2018. The copyright holder for this preprint (which was not certified by peer review) is the author/funder, who has granted bioRxiv a license to display the preprint in perpetuity. It is made available under aCC-BY-NC-ND 4.0 International license.

BioRxiv: SQ-QS, Effectors and ATM

disordered regions of the AADk substrates. For this, the number of occurrences in the real sequences was compared to occurrences in a set of background sequences, generated by shuffling the sequences of the disordered regions of each substrate 10,000 times (scrambled sequences). By scrambling the sequences, any resultant S/TQs have appeared by chance. The occurrences in these randomized sequences model the theoretical frequencies of SQs and QSs (together with the frequencies of all 400 possible dipeptides). We found that $S Q$ sites are enriched in the substrates (1- ecdf(SQ) $=0.0225$ ) (Figure 3A, Figure S2); however, QS and QT motifs are underrepresented compared to randomized sequences.

The consideration of tripeptides provides an auxiliary test for the biological relevance of $S Q$ and $Q S$ occurrences. The high fraction of $S$ and $Q$ residues are expected to yield a high number of randomly occurring $S x Q$ tripeptides ( $x$ indicates any amino acid) without biological meaning. In contrast, $S Q x$ or $x S Q$ tripeptides trivially contain all functional $S Q$ sites. Comparing the occurrence of tripeptides, we found that $S x Q$ sites are less common than $S Q x$ and $x S Q$, reflecting the abundance of $S Q$ motifs with biological roles (Figure 3B, Figure S3). In particular, SQS, SQP, SQE, and SSQ are the top-scoring tripeptides (1 ecdf(SQS, SQP, SQE, SSQ) = <0.0166, 0.0166, 0.033, 0.5, respectively) (Figure 3B). Similarly, considering the occurrences of tetrapeptides (e.g. SxxQ), the top-scoring peptides corresponded to the placement of X'S that do not destroy the SQ motif (Figure S4). Altogether, these data show that the over-representation of S/TQs in the AADk substrates is not simply a consequence of the high proportion of Ser and Gln residues in the disordered regions, but reflects true biological function. While checking the frequency of occurrence of the S/TQ dipeptides in effectors, we observed that not all the effectors followed the same distribution pattern as seen in AADk substrates (Figure 3C). This can be possible as it seems unlikely that all effectors should act to mimic the substrates of AADks (Figure 3D). Still, we noticed that in some bacterial effectors the TQ and QT dipeptides also occur more frequently than in the scrambled set (1-ecdf(QT) $<0.0025,1$ $\operatorname{ecdf}(T Q)=0.0075)$.

\section{Uneven distribution of SQ-QS distances indicates a possible biological role}

Our observation that S/TQs often appear close to QS/Ts in the sequences of the substrates and the effectors (Figure 1, Figure 4, Figure S5-S7) motivated us to check the distances between S/TQs and QS/Ts in general. The distance between an S/TQ site and the closest QS/T site is hereafter referred to as "SQ-QS distance". The significance assessment of SQ-QS distances was performed by calculating the $p$-values using the Chi-square test. The theoretical distribution of the SQ-QS distances was compared to both the distribution of SQ-QS distances from the experimentally validated phosphosites and the distribution of the SQ-QS distances from all the ST/Qs and QS/Ts in the disordered regions of the substrates. We observed that the $p$-value was lower in the former than in the latter (Chi-square test $p$-value $=0.00631$ and 0.0278 respectively; Figure S8). The lower $p$-value of SQ-QS distances in the experimentally validated phosphosites suggests a previously unknown potential biological function for $Q S / T$, that is correlated with the function of $S / T Q$ sites. 
bioRxiv preprint doi: https://doi.org/10.1101/364117; this version posted August 2, 2018. The copyright holder for this preprint (which was not certified by peer review) is the author/funder, who has granted bioRxiv a license to display the preprint in perpetuity. It is made available under aCC-BY-NC-ND 4.0 International license.

BioRxiv: SQ-QS, Effectors and ATM

\section{$\mathrm{pS} / \mathrm{TQ}$ sites are embedded in characteristic protein regions}

To investigate the possible AADk-substrate mimicry, we extensively studied the features of the pS/TQs in the substrates of the AADks.

In order to become phosphorylated, phosphorylation sites have to be located in the accessible sequence regions. This accessibility is usually accomplished by the integration of the site into an intrinsically disordered region of the protein, similarly to the examples shown in Figure 1. The majority of the experimentally verified $p S / T Q s$ are located in predicted disordered regions. Approximately $80 \%$ of the experimentally verified pS/TQs have an IUPred score $\geq 0.4$ (Figure S9). It is worth noting that some of the pS/TQs (20\%) which are in ordered regions might project from the accessible region of a secondary structure element. However, as there is insufficient structural data to back up this hypothesis, we focused our analysis to the S/TQs located in disordered regions.

The analysis of the sequences of the AADk substrates revealed that S/TQs in the disordered regions of the AADk substrates are more conserved than the S/TQs in proteins that do not interact with the AADks (Table S2). A similar trend was found for QS/Ts (Table S2). Interestingly, for TQ and QT we did not find a significant difference (Table S2). We also noticed that in the sequence $X X X X X X X p S / T Q X X X X X X$, where $p S / T$ is the experimentally validated phosphorylated residue, $60.54 \%$ of the cases have at least one additional verified phosphorylation site. The number of these additional sites varies from $1(47.51 \%)$ to $6(1 \%)$; furthermore, they are equally distributed $\mathrm{N}$ - or C- terminally to the $\mathrm{pS} / \mathrm{T}$.

Should the effectors be phosphorylated by the AADks, they can be expected to display these characteristics.

\section{Bacterial effectors might mimic AADk cellular substrates}

We noticed that bacterial effectors resemble AADk substrates in terms of motif distribution: conserved S/TQs often appear close to conserved QS/Ts in disordered protein regions (Figure 1, Figure 4, Figure S5-S7). Furthermore, these sites are embedded in sequence regions that generally resemble host proteins. To show this, we checked for similarities between the amino acid compositions of the disordered regions of human proteins and selected pathogenic bacterial proteomes (Legionella pneumophila, Chlamydia trachomatis, Coxiella burnetii and Pseudomonas syringae pv. tomato). We did not find significant differences (Kruskal-Wallis $p$-value $>0.6$ for all comparisons, Table S3), suggesting that while in general human and bacterial sequence compositions can highly differ, this difference is minimal considering disordered protein regions. It should be noted that bacteria use far fewer disordered proteins, but those they do, appear to have similar characteristics to the human disorderome.

We identified 10 bacterial effectors from human and plant pathogens that showed properties similar to the AADk multi-site substrates (Table S1; Figure 3D). We found eight different effectors from human pathogens: yhhA and Tir from enteropathogenic Escherichia coli; map from Escherichia coli O103:H2 (Verotoxigenic E. coli); CagA from Helicobacter pylori; sidG, Ipg2844 and Ipg2577 from Legionella pneumophila; and VPA1357 from Vibrio parahaemolyticus. yhhA is an experimentally validated effector from EPEC (47) but its function remains unknown. Interestingly, the sequence alignment 
generated using yhhA and its homologs shows that $S T / Q$ and $Q S / T$ sites are well conserved across different pathogenic species (Figure 4A). We also noticed that in several cases, S/TQ and QS/T sites are conserved among closely related pathogens, and they even persist in the more divergent species, although their locations in the sequence may change (Figure S5-S7). Among the plant effectors, PopA and PopB are two experimentally validated cases $(48,49)$ from Ralstonia solanacearum, an economically important pathogen that infects several crops. PopB also shows conserved ST/Q and QS/T motifs across different members of Ralstonia genus (Figure 4B).

Taking all these data into consideration, many bacterial effectors appear to have the properties of eukaryotic AADk substrates and may be mimicking their cellular substrate $\mathrm{S} / \mathrm{TQ}$ motifs.

\section{DISCUSSION}

Bacteria can mimic features of eukaryotic proteins in order to take advantage of the molecular machinery of the host cell during infection. This concept is well established for effectors such as Tir from the Enteropathogenic Escherichia coli (EPEC) (35). The Cterminal region of Tir shares similarity with the cellular Immunoreceptor Tyrosine-based Inhibition Motifs (ITIMs) which play a pivotal role in actin polymerisation. We have now found that bacterial effectors show conserved S/TQ motifs across different species of pathogenic bacteria (Figure 4), marking them as potential substrates of human AADks. During our analysis we observed that conserved S/TQs are present in both human (Legionella pneumophila, Escherichia coli, Vibrio parahaemolyticus and Helicobacter pylori) and plant pathogens (Ralstonia solanacearum). Given that S/TQs are phosphorylated by AADks, we suppose that these sites could be phosphorylated by the host kinases. There is evidence that some bacteria, such as Salmonella typhi (50) and different strains of E.coli possess toxins with dsDNase activity such as the CDT toxin (51). Moreover, some plant pathogens have been reported to be able to cause DNA doublestrand breaks, and ATM and ATR double mutants are more susceptible to infection than the wild-type plants (52). However, many more effectors with SQ motifs are present in human and plant pathogens that may not be directly damaging the host cell DNA.

For example, we found that Shigella dysenteriae, Enterohemorrhagic E. coli and EPEC all possess a small S/TQ-rich effector (yhhA and map) which might interact with ATM, interfering with its signalling pathway, resulting in a possible advantage for the bacteria. Oxidative stress is an essential factor for gastrointestinal mucosal diseases caused by pathogenic bacteria such as Shigella or E.coli (53). ATM plays a key role in oxidative stress response $(4 ; 5)$ and the activation of its downstream pathway could either compromise, or enhance, the entire infection process. This hypothesis is supported by the cytoplasmic presence of AADks and their possible involvement in immune response $(10-14)$ suggesting that their function is not limited to DNA damage response or cell cycle regulation. While the majority of the phosphorylation sites in eukaryotes must be accessible to the kinase (Figure S9) being in disordered regions or on the accessible surface region of domains, in bacteria some of the $S Q$ sites could be phosphorylated even though they are embedded in ordered regions due to the fact that type III effectors enter unfolded into the target cell (54). Nevertheless, in order to obtain strong candidates, we decided to only consider candidate motifs in disordered regions during our analysis. Our analysis was complicated by the observation that QS/T motifs seemed to be associated with the S/TQ sites. We were able to show that these two motifs do 
bioRxiv preprint doi: https://doi.org/10.1101/364117; this version posted August 2, 2018. The copyright holder for this preprint (which was not certified by peer review) is the author/funder, who has granted bioRxiv a license to display the preprint in perpetuity. It is made available under aCC-BY-NC-ND 4.0 International license.

BioRxiv: SQ-QS, Effectors and ATM

significantly cluster together in both the cellular substrate sets and in the bacterial effectors. We were also quickly able to find multiple examples of S/TQ-rich proteins in both animal- and plant-infecting pathogens.

A W1FS96|EPEC
A0A0F6B818|S.typ
H5V3H1|A.her
A0A085G002|B.agr
W0BEB0|E.clo
A8AR00|C.kos
A0A0G3QMZ|K.int
D2A9P5|S.fle
Q32AT6|S.dys
C8UHS8 |E.coli
P0ADX7|E.coli
D4BI74|C.you
A0A1C0PGMO|C.fre
W1B950|K.pne

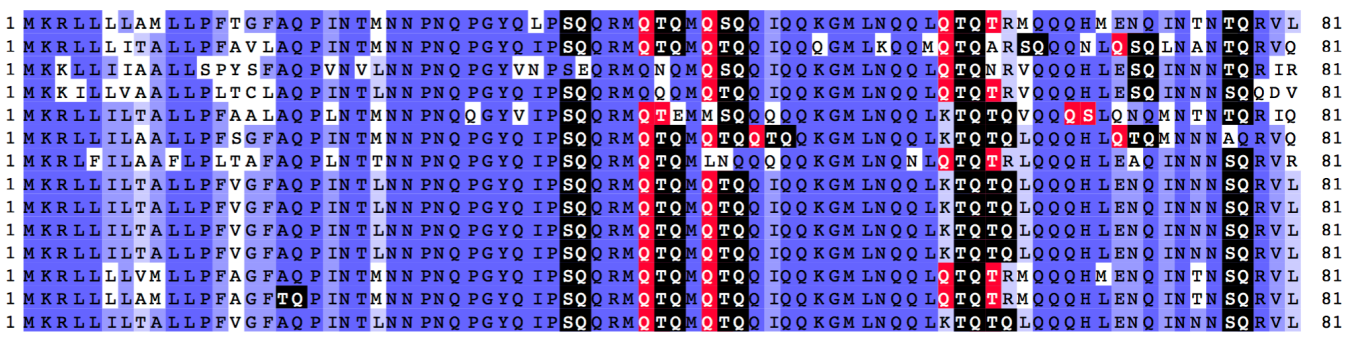

W1FS96|EPEC

A0A0F6B818|S.tyP

H5V3H1|A.her

A0A085G002|B.agr

WOBEBO|E.clo

AOAOGOMMO|K.int

D2A9P5|S.fle

Q32AT6|S.dys

C8UHS8|E.coli

P0ADX7|E.coli

A0A1COPGMO|C.fre

W1B950|K.pne

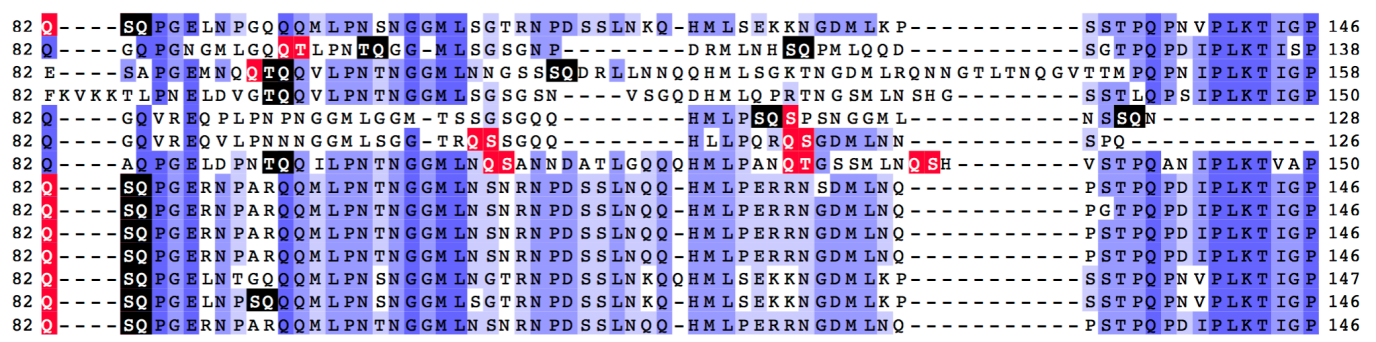

B

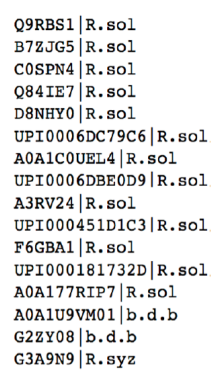

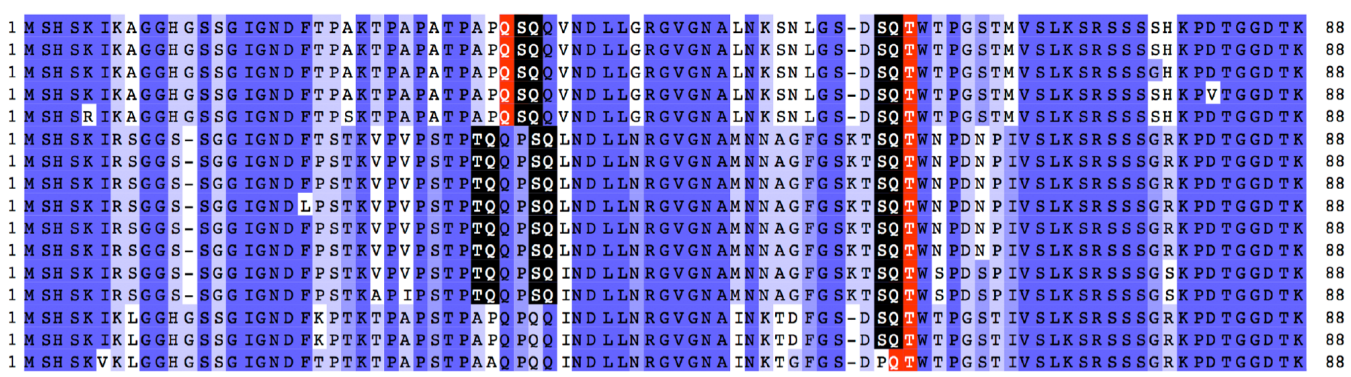

Q9RBS1|R.sol

B7ZJG5|R.sol

COSPN 4 R. Sol

Q84IE7|R. Sol

D8NHY0|R.sol
UPI0006DC79C6 $\mid$ R.sol

UPI0006DC79C6 $\mid$ R.s

UPI0006DBEDQ $\mid$ R.sOL

UPI0006DBE0D

A3RV24|R.sol

F6GBA1|R.sol

F6GBA1 $\mid$ R. SOl
UPI000181732D|R.sol

A0A177RIP7|R.sol

A0A1U9VM01|b.d.b

G2ZY08|b.d.b

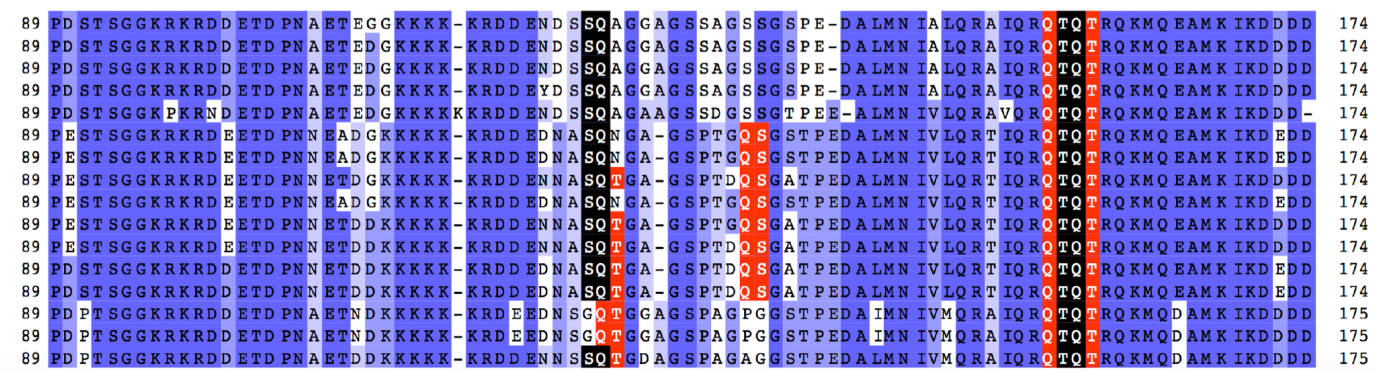

Figure 4. Panel A shows an alignment for yhhA from Enteropathogenic E.coli (EPEC), and its homolog from Atlantibacter hermanni (A.her), Buttiauxella agrestis (B.agr), Enterobacter cloacae (E.clo), Citrobacter koseri (C.kos), Kluyvera intermedia (K.int), Shigella flexneri (S.fle), Shigella dysenteriae serotype 1 (S.dys), Escherichia coli (E.coli), Salmonella enterica Typhimurium (S.typ), Citrobacter freundii (C.fre), Klebsiella pneumoniae (K.pne). Panel B shows possible AADk phosphorylation sites in PopB (Q9RBS1) from different strains of Ralstonia solanacearum (R.sol), Banana Blood Disease Bactetrium (b.d.b) and Ralstonia syzygii (R.syz). S/ TQs are highlighted in black, QS/Ts in red. The motifs cluster together and often overlap. These proteins are predicted to be natively disordered. Blue marks the percentage of identity for all other residues. Uniprot and UniRef accessions have been provided for the sequences.

Most of these proteins are not yet known to be effectors (data not shown) though. The alignments show that both in human cellular proteins and in the bacterial proteins, when there are $S / T Q$ clusters, the $Q S / T$ motif always clusters too. The function for $Q S / T$ is still unknown but the clustering suggests it could have a function linked to the phosphorylation of S/TQ. We noticed, in addition, that the theoretical distribution of $S / T Q-Q S / T$ distances differ significantly from the observed one. An experimentally validated docking motif for PIKK kinases was reported by Falk et al. (2005) but is only present in a few of the known nuclear substrates (10 out of 152). QS/T seems too simple to be a pure docking motif, such as the one found in MAPK substrates (55). 
bioRxiv preprint doi: https://doi.org/10.1101/364117; this version posted August 2, 2018. The copyright holder for this preprint (which was not certified by peer review) is the author/funder, who has granted bioRxiv a license to display the preprint in perpetuity. It is made available under aCC-BY-NC-ND 4.0 International license.

\section{BioRxiv: SQ-QS, Effectors and ATM}

One possible role could be to act as a docking-activating or (perhaps less likely) a dockinginhibitory site. However, a few of the known cellular substrates (12 out of 152) do not have any $\mathrm{QS} / \mathrm{Ts}$ in their sequences. This includes the key DNA damage protein H2AX. In such a scenario, the motif might work in trans because, before it can phosphorylate $\mathrm{H} 2 \mathrm{AX}, \mathrm{ATM}$ is docked to the damage site by NBS1 (56), which is itself also an ATM substrate with 6 copies of the QS/T motif.

Given the somewhat weak statistical results we were worried about the obvious temptation to try too many different tests. This would inevitably lead to a multiple testing problem. Finally, the motifs in the bacterial proteins show a broad range of conservation, with some motifs being very conserved and others partially or poorly. But in many cases, motifs would persist in all the sequences even if they were not conserved. It is well known that SLiMs can change position by evolutionary resampling: duplication followed by loss of the original (57). This suggests that there is a need to develop an evolutionary "motif persistence" score for these very simple sequence motifs.

In the preprint, we have reported several pieces of evidence that could suggest an interplay between bacterial effectors and the ATM kinase family. Bioinformatics analyses do not prove the function of a motif candidate and, as a consequence, they must be experimentally validated. If the AADk usage proves to be widespread in pathogens, then the oxidative stress signaling is likely to be an important part of that function. It will need to be established whether the pathogens actively promote oxidative stress to their advantage (53) or whether it is a side effect of infection that needs to be controlled. Tissue culture experiments with oxidants like hydrogen peroxide or antioxidants such as $\mathrm{N}$-acetyl cysteine might show altered infectivity. In addition, the availability of ATM kinase inhibitors such as KU-55933 (58) will be useful for phosphorylation experiments.

\section{ACKNOWLEDGMENTS}

The authors thank Dr. Bernd Klaus for discussing statistical issues. DS thanks fellowship from the Erasmus+ Program. BM acknowledges support from the EMBO|EuropaBio fellowship 7544. MK is thankful to the Humboldt Foundation for post-doctoral research fellowship.

\section{REFERENCES}

1. Lempiäinen,H. and Halazonetis,T.D. (2009) Emerging common themes in regulation of PIKKs and PI3Ks. EMBO J., 28, 3067-3073.

2. Lee,J.-H. and Paull,T.T. (2007) Activation and regulation of ATM kinase activity in response to DNA double-strand breaks. Oncogene, 26, 7741-7748.

3. Sancar,A., Lindsey-Boltz,L.A., Unsal-Kaçmaz,K. and Linn,S. (2004) Molecular mechanisms of mammalian DNA repair and the DNA damage checkpoints. Annu. Rev. Biochem., 73, 39-85.

4. Guo,Z., Kozlov,S., Lavin,M.F., Person,M.D. and Paull,T.T. (2010) ATM activation by oxidative stress. Science, 330, 517-521.

5. Ditch,S. and Paull,T.T. (2012) The ATM protein kinase and cellular redox signaling: beyond the DNA damage response. Trends Biochem. Sci., 37, 15-22.

6. Yang,D.-Q., Halaby,M.-J., Li,Y., Hibma,J.C. and Burn,P. (2011) Cytoplasmic ATM protein kinase: an emerging therapeutic target for diabetes, cancer and neuronal degeneration. Drug Discov. Today, 16, 332-338.

7. Alexander,A., Cai,S.-L., Kim,J., Nanez,A., Sahin,M., MacLean,K.H., Inoki,K., Guan,K.-L., Shen,J., Person,M.D., et al. (2010) ATM signals to TSC2 in the cytoplasm to regulate mTORC1 in response to ROS. Proc. Natl. Acad. Sci. U.S.A., 107, 4153-4158. 
bioRxiv preprint doi: https://doi.org/10.1101/364117; this version posted August 2, 2018. The copyright holder for this preprint (which was not certified by peer review) is the author/funder, who has granted bioRxiv a license to display the preprint in perpetuity. It is made available under aCC-BY-NC-ND 4.0 International license.

\section{BioRxiv: SQ-QS, Effectors and ATM}

8. Alexander,A. and Walker,C.L. (2010) Differential localization of ATM is correlated with activation of distinct downstream signaling pathways. Cell Cycle, 9, 3685-3686.

9. Hilton,B.A., Li,Z., Musich,P.R., Wang,H., Cartwright,B.M., Serrano,M., Zhou,X.Z., Lu,K.P. and Zou,Y. (2016) ATR Plays a Direct Antiapoptotic Role at Mitochondria, which Is Regulated by Prolyl Isomerase Pin1. Mol. Cell, 61, 487.

10. Ferguson,B.J., Mansur,D.S., Peters,N.E., Ren,H. and Smith,G.L. (2012) DNA-PK is a DNA sensor for IRF-3-dependent innate immunity. Elife, 1, e00047.

11. Choy,K.R. and Watters,D.J. (2018) Neurodegeneration in ataxia-telangiectasia: Multiple roles of ATM kinase in cellular homeostasis. Dev. Dyn., 247, 33-46.

12. Boder,E. and Sedgwick,R.P. (1958) Ataxia-telangiectasia; a familial syndrome of progressive cerebellar ataxia, oculocutaneous telangiectasia and frequent pulmonary infection. Pediatrics, 21, 526-554.

13. Erttmann,S.F., Härtlova,A., Sloniecka,M., Raffi,F.A.M., Hosseinzadeh,A., Edgren,T., Rofougaran,R., Resch,U., Fällman,M., Ek,T., et al. (2016) Loss of the DNA Damage Repair Kinase ATM Impairs Inflammasome-Dependent Anti-Bacterial Innate Immunity. Immunity, 45, 106-118.

14. Yeo,A.J., Fantino,E., Czovek,D., Wainwright,C.E., Sly,P.D. and Lavin,M.F. (2017) Loss of ATM in Airway Epithelial Cells Is Associated with Susceptibility to Oxidative Stress. Am. J. Respir. Crit. Care Med., 196, 391-393.

15. Cortes-Bratti,X., Karlsson,C., Lagergård,T., Thelestam,M. and Frisan,T. (2001) The Haemophilus ducreyi cytolethal distending toxin induces cell cycle arrest and apoptosis via the DNA damage checkpoint pathways. J. Biol. Chem., 276, 5296-5302.

16. Thatte,J., Massimi,P., Thomas,M., Boon,S.S. and Banks,L. (2018) The HPV E6 PDZ Binding Motif links DNA Damage Response Signaling to E6 Inhibition of p53 Transcriptional Activity. J. Virol.

17. Kim,S.T., Lim,D.S., Canman,C.E. and Kastan,M.B. (1999) Substrate specificities and identification of putative substrates of ATM kinase family members. J. Biol. Chem., 274, 3753837543.

18. Davey,N.E., Van Roey,K., Weatheritt,R.J., Toedt,G., Uyar,B., Altenberg,B., Budd,A., Diella,F., Dinkel,H. and Gibson,T.J. (2012) Attributes of short linear motifs. Mol Biosyst, 8, 268-281.

19. Gibson,T.J., Dinkel,H., Van Roey,K. and Diella,F. (2015) Experimental detection of short regulatory motifs in eukaryotic proteins: tips for good practice as well as for bad. Cell Commun. Signal, 13, 42.

20. Murray,D.T., Kato,M., Lin,Y., Thurber,K.R., Hung,I., McKnight,S.L. and Tycko,R. (2017) Structure of FUS Protein Fibrils and Its Relevance to Self-Assembly and Phase Separation of Low-Complexity Domains. Cell, 171, 615-627.e16.

21. Sharma,A., Singh,K. and Almasan,A. (2012) Histone H2AX phosphorylation: a marker for DNA damage. Methods Mol. Biol., 920, 613-626.

22. Galán,J.E. (2009) Common themes in the design and function of bacterial effectors. Cell Host Microbe, 5, 571-579.

23. Casadevall,A. and Pirofski,L.A. (2000) Host-pathogen interactions: basic concepts of microbial commensalism, colonization, infection, and disease. Infect. Immun., 68, 6511-6518.

24. Costa,T.R.D., Felisberto-Rodrigues,C., Meir,A., Prevost,M.S., Redzej,A., Trokter,M. and Waksman,G. (2015) Secretion systems in Gram-negative bacteria: structural and mechanistic insights. Nat. Rev. Microbiol., 13, 343-359.

25. Green,E.R. and Mecsas,J. (2016) Bacterial Secretion Systems: An Overview. Microbiol Spectr, 4.

26. Houben,E.N.G., Korotkov,K.V. and Bitter,W. (2014) Take five - Type VII secretion systems of Mycobacteria. Biochim. Biophys. Acta, 1843, 1707-1716.

27. Papanikou,E., Karamanou,S. and Economou,A. (2007) Bacterial protein secretion through the translocase nanomachine. Nat. Rev. Microbiol., 5, 839-851.

28. Robinson,C. and Bolhuis,A. (2004) Tat-dependent protein targeting in prokaryotes and chloroplasts. Biochim. Biophys. Acta, 1694, 135-147.

29. Erhardt,M. (2017) Energy Requirements for Protein Secretion via the Flagellar Type III Secretion System. Methods Mol. Biol., 1615, 449-457. 
30. Ruchaud-Sparagano,M.-H., Mühlen,S., Dean,P. and Kenny,B. (2011) The enteropathogenic E. coli (EPEC) Tir effector inhibits NF-KB activity by targeting TNFa receptor-associated factors. PLoS Pathog., 7, e1002414.

31. Saito,Y., Murata-Kamiya,N., Hirayama,T., Ohba,Y. and Hatakeyama,M. (2010) Conversion of Helicobacter pylori CagA from senescence inducer to oncogenic driver through polaritydependent regulation of p21. J. Exp. Med., 207, 2157-2174.

32. Davey,N.E., Travé,G. and Gibson,T.J. (2011) How viruses hijack cell regulation. Trends Biochem. Sci., 36, 159-169.

33. Higashi,H., Yokoyama,K., Fujii,Y., Ren,S., Yuasa,H., Saadat,I., Murata-Kamiya,N., Azuma,T. and Hatakeyama,M. (2005) EPIYA motif is a membrane-targeting signal of Helicobacter pylori virulence factor CagA in mammalian cells. J. Biol. Chem., 280, 23130-23137.

34. Chmiela,M. and Gonciarz,W. (2017) Molecular mimicry in Helicobacter pylori infections. World J. Gastroenterol., 23, 3964-3977.

35. Smith,K., Humphreys,D., Hume,P.J. and Koronakis,V. (2010) Enteropathogenic Escherichia coli recruits the cellular inositol phosphatase SHIP2 to regulate actin-pedestal formation. Cell Host Microbe, 7, 13-24.

36. Gouw,M., Michael,S., Sámano-Sánchez,H., Kumar,M., Zeke,A., Lang,B., Bely,B., Chemes,L.B., Davey,N.E., Deng,Z., et al. (2018) The eukaryotic linear motif resource - 2018 update. Nucleic Acids Res., 46, D428-D434.

37. Hornbeck,P.V., Zhang,B., Murray,B., Kornhauser,J.M., Latham,V. and Skrzypek,E. (2015) PhosphoSitePlus, 2014: mutations, PTMs and recalibrations. Nucleic Acids Res., 43, D512-520.

38. Dinkel,H., Chica,C., Via,A., Gould,C.M., Jensen,L.J., Gibson,T.J. and Diella,F. (2011) Phospho.ELM: a database of phosphorylation sites--update 2011. Nucleic Acids Res., 39, D261267.

39. An,Y., Wang,J., Li,C., Revote,J., Zhang,Y., Naderer,T., Hayashida,M., Akutsu,T., Webb,G.I., Lithgow,T., et al. (2017) SecretEPDB: a comprehensive web-based resource for secreted effector proteins of the bacterial types III, IV and VI secretion systems. Sci Rep, 7, 41031.

40. UniProt Consortium,T. (2018) UniProt: the universal protein knowledgebase. Nucleic Acids Res., 46, 2699.

41. Sievers,F., Wilm,A., Dineen,D., Gibson,T.J., Karplus,K., Li,W., Lopez,R., McWilliam,H., Remmert,M., Söding,J., et al. (2011) Fast, scalable generation of high-quality protein multiple sequence alignments using Clustal Omega. Mol. Syst. Biol., 7, 539.

42. Waterhouse,A.M., Procter,J.B., Martin,D.M.A., Clamp,M. and Barton,G.J. (2009) Jalview Version 2--a multiple sequence alignment editor and analysis workbench. Bioinformatics, 25, $1189-1191$.

43. Davey,N.E., Cowan,J.L., Shields,D.C., Gibson,T.J., Coldwell,M.J. and Edwards,R.J. (2012) SLiMPrints: conservation-based discovery of functional motif fingerprints in intrinsically disordered protein regions. Nucleic Acids Res., 40, 10628-10641.

44. Mészáros,B., Erdos,G. and Dosztányi,Z. (2018) IUPred2A: context-dependent prediction of protein disorder as a function of redox state and protein binding. Nucleic Acids Res..

45. Hatakeyama,M. (2017) Structure and function of Helicobacter pylori CagA, the first-identified bacterial protein involved in human cancer. Proc. Jpn. Acad., Ser. B, Phys. Biol. Sci., 93, 196219.

46 Midic U. Obradovic Z (2012) Intrinsic disorder in putative protein sequences. Proteome sci., 10, Suppl 1

47. Deng,W., Yu,H.B., de Hoog,C.L., Stoynov,N., Li,Y., Foster,L.J. and Finlay,B.B. (2012) Quantitative proteomic analysis of type III secretome of enteropathogenic Escherichia coli reveals an expanded effector repertoire for attaching/effacing bacterial pathogens. Mol. Cell Proteomics, 11, 692-709.

48. Arlat,M., Van Gijsegem,F., Huet,J.C., Pernollet,J.C. and Boucher,C.A. (1994) PopA1, a protein which induces a hypersensitivity-like response on specific Petunia genotypes, is secreted via the Hrp pathway of Pseudomonas solanacearum. EMBO J., 13, 543-553.

49. Guéneron,M., Timmers,A.C., Boucher,C. and Arlat,M. (2000) Two novel proteins, PopB, which has functional nuclear localization signals, and $\mathrm{PopC}$, which has a large leucine-rich repeat 
bioRxiv preprint doi: https://doi.org/10.1101/364117; this version posted August 2, 2018. The copyright holder for this preprint (which was not certified by peer review) is the author/funder, who has granted bioRxiv a license to display the preprint in perpetuity. It is made available under aCC-BY-NC-ND 4.0 International license.

BioRxiv: SQ-QS, Effectors and ATM

domain, are secreted through the hrp-secretion apparatus of Ralstonia solanacearum. Mol. Microbiol., 36, 261-277.

50. Haghjoo,E. and Galán,J.E. (2004) Salmonella typhi encodes a functional cytolethal distending toxin that is delivered into host cells by a bacterial-internalization pathway. Proc. Natl. Acad. Sci. U.S.A., 101, 4614-4619.

51. El-Aouar Filho,R.A., Nicolas,A., De Paula Castro,T.L., Deplanche,M., De Carvalho Azevedo,V.A., Goossens,P.L., Taieb,F., Lina,G., Le Loir,Y. and Berkova,N. (2017) Heterogeneous Family of Cyclomodulins: Smart Weapons That Allow Bacteria to Hijack the Eukaryotic Cell Cycle and Promote Infections. Front Cell Infect Microbiol, 7, 208.

52. Song,J. and Bent,A.F. (2014) Microbial pathogens trigger host DNA double-strand breaks whose abundance is reduced by plant defense responses. PLoS Pathog., 10, e1004030.

53. Bhattacharyya A., Chattopadhyay R, Mitra S, and Crowe E. S (2014) Oxidative Stress: An Essential Factor in the Pathogenesis of Gastrointestinal Mucosal Diseases, Physiol Rev.; 94(2): 329-354

54. Marlovits,T.C., Kubori,T., Sukhan,A., Thomas,D.R., Galán,J.E. and Unger,V.M. (2004) Structural insights into the assembly of the type III secretion needle complex. Science, 306, 10401042.

55. Tanoue,T., Adachi,M., Moriguchi,T. and Nishida,E. (2000) A conserved docking motif in MAP kinases common to substrates, activators and regulators. Nat. Cell Biol., 2, 110-116.

56. You,Z., Chahwan,C., Bailis,J., Hunter,T. and Russell,P. (2005) ATM activation and its recruitment to damaged DNA require binding to the $C$ terminus of Nbs1. Mol. Cell. Biol., 25, 5363-5379.

57. Davey,N.E., Cyert,M.S. and Moses,A.M. (2015) Short linear motifs - ex nihilo evolution of protein regulation. Cell Commun. Signal, 13, 43.

58. Hickson,I., Zhao,Y., Richardson,C.J., Green,S.J., Martin,N.M.B., Orr,A.I., Reaper,P.M., Jackson,S.P., Curtin,N.J. and Smith,G.C.M. (2004) Identification and characterization of a novel and specific inhibitor of the ataxia-telangiectasia mutated kinase ATM. Cancer Res., 64, 91529159. 